\title{
Effect on Placental Transfer of Exogenous Lipid Administered to the Pregnant Rabbit
}

\author{
JULIE STAMMERS, TERENCE STEPHENSON, JULIE COLLEY, AND DAVID HULL \\ Department of Child Health, University Hospital and Medical School, Nottingham NG7 2UH, \\ United Kingdom
}

\section{ABSTRACT}

\begin{abstract}
The transfer of lipids across the placenta was measured after infusion of an emulsion of triacylglycerol and phospholipid (Intralipid) into 10 anesthetized rabbits. Maternal and umbilical venous and arterial samples were collected at 10-min intervals. All samples were analyzed for concentration and fatty acid composition of FFA, triacylglycerol, and phospholipid fractions. At the end of the infusion period of Intralipid, there was a significant increase in the maternal concentrations of total triacylglycerol $(p<0.01)$ and of total phospholipid $(p=0.01)$ but not of total FFA $(p>0.05)$. Maternal plasma triacylglycerol and phospholipid altered in composition to match that of the infused Intralipid by the end of the infusion. Despite the significant rise in maternal triacylglycerol and phospholipid concentrations, the
\end{abstract}

umbilical vein-artery difference for these lipid fractions remained unchanged and very low. In contrast, the umbilical vein-artery difference for FFA $(p<0.02)$ rose gradually throughout the experiments. There was no significant change in the fatty acid composition of the maternal FFA, but the fatty acid composition of the umbilical vein-artery difference for FFA changed to reflect the composition of Intralipid. These experiments show that exogenous triacylglycerol and phospholipid dramatically alter the lipid fractions presented to the placenta in the maternal plasma but do not cross the placenta intact. However, the composition of the FFA crossing the placenta is modulated to become more similar to that of the exogenous lipid. (Pediatr Res 38: 10261031, 1995)
Factors related to adult lifestyle, such as diet, smoking, and lack of exercise, have been seen as the major risk factors for ischemic heart disease (1). However, recent epidemiologic evidence has suggested that some of the risk of cardiovascular disease in adulthood is related to fetal growth and infant feeding (2-3). Experiments in animals have shown that, after birth, different early feeding regimes can lead to permanent changes in plasma lipid concentrations and in the activity of enzymes controlling cholesterol metabolism (4-6). It may be therefore that, earlier in life, fetal nutrition may also program lipid metabolism in adulthood.

One group of infants particularly at risk of cardiovascular mortality in later life are those who suffer from intrauterine growth retardation (3). At present there are few therapeutic interventions available which improve the fetal growth of these infants (7). One option is to try to increase placental transfer of nutrients to the fetus by supplementation of maternal nutrition (8). We have developed the technique of in situ perfusion of the rabbit placenta which allows examination of transfer from mother to fetus under closely controlled conditions $(9,10)$. We report a series of experiments in which direct measurements of the transfer of lipids across the placenta were made serially

Received November 22, 1994; accepted June 1, 1995.

Correspondence and reprint requests: Dr. Julie Stammers, Department of Child Health, University Hospital and Medical School, Nottingham NG7 2UH, UK. after infusion of an emulsion of triacylglycerol and phospholipid into the mother.

\section{METHODS}

Experimental. Ten New Zealand White/Californian rabbits were studied at $28-\mathrm{d}$ gestation (term $=31 \mathrm{~d}$ ). The surgical methods used have been previously described (9).

Maternal preparation. The doe was placed on a heated table, and the body temperature was maintained throughout the experiment at $38^{\circ} \mathrm{C}$, monitored by a rectal thermocouple. A 24 gauge catheter (Critikon Ltd, Berks) was inserted into a marginal ear vein, and anesthesia was induced with $5 \mathrm{~mL} / \mathrm{kg}$ of $20 \%$ (wt/vol) ethyl carbamate (Urethane, Sigma Chemical Co. Co, Poole, Dorset). A tracheotomy was performed, and an 18 gauge catheter (Critikon Ltd, Berks) was inserted into the left carotid artery for blood pressure monitoring and maternal sampling. The catheter was kept patent by an infusion of 1 $\mathrm{mL} / \mathrm{h}$ of $0.9 \%(\mathrm{wt} / \mathrm{vol})$ saline. Heparin, which is known to activate lipoprotein lipase, was not used at any stage of the experiments. Further doses of ethyl carbamate were given as required up to a maximum of $8 \mathrm{~mL} / \mathrm{kg}$. Antipyrine (Sigma Chemical Co. Co, Poole, Dorset) was infused into a marginal ear vein throughout the duration of the experiment. Antipyrine concentrations were measured in the maternal plasma and perfusate samples to monitor the stability of the placental exchange unit. 
Placental preparation. A laparotomy was performed, and one fetus was withdrawn through a longitudinal incision in the uterus and delivered onto the abdomen of the doe. The umbilical arteries and vein were cannulated with 22 gauge and 20 gauge catheters (Argyle Medicut, Sherwood Medical Industries), respectively. The exposed uterus and placenta were kept moist and at body temperature by a radiant heat source and a plastic cover. The uterine temperature was monitored throughout the experiment using a thermocouple.

Perfusion of the placenta. The fetal placental circulation was perfused at $1 \mathrm{~mL} / \mathrm{min}$ with $4 \%$ bovine albumin in Kreb's Henseleit bicarbonate saline (the "perfusate") via both umbilical artery catheters using a peristaltic pump. The perfusate was gassed continuously with $95 \% \mathrm{O}_{2} / 5 \% \mathrm{CO}_{2}$, and the $\mathrm{pH}$ was adjusted to 7.4 using a Tris combination electrode ( $\mathrm{pH}$ electrode EL 69B, Waldren Precision Apparatus Ltd, Cambridge) suitable for protein solutions. The bovine albumin was not fat-free. The initial fatty acid concentration in the $4 \%$ solution was measured in each experiment (mean $0.19 \mathrm{mmol} / \mathrm{L}$ FFA, $0.06 \mathrm{mmol} / \mathrm{L}$ triacylglycerol, and $0.04 \mathrm{mmol} / \mathrm{L}$ phospholipid).

Infusion of Intralipid. After 20 min of placental perfusion, to allow the preparation to stabilize, baseline FFA, triacylglycerol, and phospholipid concentrations were measured in the perfusate flowing out of the umbilical venous catheter. The same biochemical measurements were made on the artificial perfusate flowing into the umbilical arterial catheters from the reservoir. The difference between the inflowing and outflowing concentrations represents the net lipids added to the umbilical circulation from the placenta. After collection of these baseline samples, an infusion of $5 \mathrm{~mL}$ of $20 \%$ Intralipid was given i.v. to the doe over $10 \mathrm{~min}$. Further maternal and umbilical venous samples were collected at the end of the infusion period and at 10 -min intervals thereafter for the following $40 \mathrm{~min}$.

FFA profiles. A modification of the method described by Elphick et al. (11) was used to measure fatty acid concentrations and composition. A 500- $\mu \mathrm{L}$ sample of plasma or perfusate was extracted into redistilled $n$-heptane according to the method of Dole (12). Fatty acid soaps were formed by the addition of $0.015 \mathrm{M}$ sodium hydroxide to the extracted fatty acids. The water-soluble soaps were extracted into an ethanolaqueous phase. To convert the soaps back to the acid form, 0.1 $M$ sulfuric acid was added, and the FFA was extracted into pentane (Distol reagent, Fisons Plc, Loughborough, Leics.). The extract was dried, and boron trifluoride methanol complex (Fisons Plc, Loughborough, Leics.) was added. The tubes were gassed with oxygen-free nitrogen, tightly stoppered, and incubated at $65^{\circ} \mathrm{C}$ for $10 \mathrm{~min}$. The fatty acid methyl esters so formed were extracted into pentane and separated by gas liquid chromatography as described below. This method allowed measurement of FFA down to $5 \times 10^{-4} \mu \mathrm{mol} / 500 \mu \mathrm{L}$ sample. The reproducibility and precision of the method was found to be 4.8 and $6.7 \%$ (coefficient of variation using measurements of 20 replicate analyses).

Triacylglycerol and phospholipid profiles. Lipids were extracted using a modification of the method of Folch et al. (13). A 1-mL sample of plasma perfusate was added to $20 \mathrm{~mL}$ of redistilled chloroform/methanol, $2: 1 \mathrm{vol} / \mathrm{vol}$, mixed well, and allowed to stand for $10 \mathrm{~min}$. Intralipid diluted 1:100 in distilled water was similarly extracted. The extracts were washed with $0.1 \mathrm{M}$ phosphate buffer ( $\mathrm{pH} 6.0$ ), and the phases were allowed to separate. The top aqueous phase containing nonlipid constituents was discarded, and the bottom chloroform phase was filtered through fat-free filter paper and washed through with redistilled chloroform/methanol, $2: 1 \mathrm{vol} / \mathrm{vol}$. The lipids in this extract were subjected to thin layer chromatography on plates coated with a 0.4-mm thick layer of Silica Gel H (Merck, BDH Ltd, Poole, Dorset) to separate out the different lipid fractions. The plates were run in tanks in which the atmosphere was equilibrated with a solvent system of hexane:diethyl ether:formic acid, 75:25:1 vol/vol, in oxygen-free nitrogen. The lipid zones were located by spraying the plates with $0.002 \%$ rhodamine 6G (Seare, High Wycombe, Bucks) in ethanol containing $1 \mathrm{~g} / \mathrm{L}$ DL- $\alpha$-tocopherol (antioxidant) (Sigma Chemical Co. Ltd, Poole, Dorset) under UV light. The phospholipid and triacylglycerol areas were scraped off and subjected to methanolysis.

The method of Glass (14) was used to prepare fatty acid methyl esters from these phospholipids and triacylglycerols. After addition of $500 \mu \mathrm{L}$ of sodium methoxide reagent (prepared by dissolving $2.3 \mathrm{~g}$ of sodium metal (BDH Ltd, Poole, Dorset) in $100 \mathrm{~mL}$ of $60 \%$ methanol/benzene, vol/vol), the samples were allowed to stand for $10 \mathrm{~min}$, and $1 \mathrm{~mL}$ of methanolic hydrochloric acid $(10 \mathrm{~mL}$ concentrated hydrochloric acid, specific gravity 1.16 made up to $100 \mathrm{~mL}$ with methanol), was added. The tubes were shaken and allowed to stand for a further $30 \mathrm{~min}$. The fatty acid methyl esters were extracted into pentane and analyzed by gas liquid chromatography as described below. This method allowed measurement of triacylglycerol and phospholipid fatty acid down to $1 \times 10^{-3}$ $\mu \mathrm{mol} / \mathrm{mL}$ sample. The reproducibility and precision of the method was found to be 4.9 and $7.1 \%$ for phospholipid and 5.9 and $9.0 \%$ for triacylglycerol, respectively (coefficient of variation using the measurement of 20 replicate analyses).

Gas liquid chromatography. A Perkin-Elmer gas chromatograph model 8410 fitted with a flame ionization detector was used to separate fatty acid methyl esters. A fused silica capillary column $30 \mathrm{~m}$ in length with an internal diameter of 0.32 mm was coated with SP2330 (bicyanopropylphenyl polysiloxane) at a film thickness of $0.2 \mu \mathrm{m}$ (Supelchem, Saffron Walden, Essex) was used. The column was run isothermally at $185^{\circ} \mathrm{C}$ with a linear gas velocity of $20 \mathrm{~cm} / \mathrm{s}$. The injection and detection temperatures were maintained at $250^{\circ} \mathrm{C}$. A split/ splitless injection system was used at a ratio of 70:1. Fatty acids were identified by comparison of their retention times with those of authenticated standards (Sigma Chemical Co.) and were quantified by comparison with an internal standard (heptadecanoic acid for FFA, triheptadecanoin for triacylglycerols, and L- $\alpha$-phosphatidylcholine diheptadecanoyl for phospholipids).

Antipyrine measurements. Antipyrine concentrations were determined in $1.0-\mathrm{mL}$ perfusate samples deproteinized with zinc hydroxide, followed by the addition of sodium nitrite and spectrophotometric measurement of 4-nitrosoantipyrine (15).

Statistical methods. Comparisons were made using nonparametric tests because the biochemical data were not normally distributed (Wilcoxon's signed rank test). Rather than make multiple paired comparisons, which are liable to falsely reject 
the null hypothesis, time-series measurements were subjected to Friedman's two-way analysis of variance.

\section{RESULTS}

Stability of the preparation. Table 1 shows a number of measures of physiologic stability documented at the beginning and end of each experiment. There was a significant fall in maternal blood pressure and maternal arterial $\mathrm{pH}$ over the duration of the experiment but placental antipyrine clearance did not change during the period of study and this suggests that maternal placental blood flow was not altered by these changes in systemic blood pressure and $\mathrm{pH}$. We have previously conducted several series of experiments which use the same anesthesia but did not involve the infusion of Intralipid to the pregnant doe $(9,10,16,17)$. All of these experiments showed no significant change in maternal blood gases, placental perfusion pressure, and maternal to umbilical antipyrine ratio. Most experiments showed a trend for maternal blood pressure to fall over a similar time course by less than $10 \%$. This change in blood pressure reached statistical significance in two series of experiments $(9,10)$. These findings illustrate the general physiologic stability of the preparation. The "cross-over" experimental design used in these studies was chosen because of the inherent variability of animals undergoing anesthesia, and given that there were no significant changes in physiologic variables in the mothers receiving Intralipid, it can be concluded that the Intralipid infusion was not significantly altering the preparation.

Total plasma lipid concentrations. At the end of the 10-min infusion period of Intralipid, there was a significant increase of total triacylglycerol ( $p<0.01$, Wilcoxon's signed rank test) and of total phospholipid ( $p=0.01$, Wilcoxon's signed rank test) in the maternal circulation (Fig. 1). Despite the significant rise in maternal triacylglycerol and phospholipid concentrations, the umbilical vein-artery difference for these lipid fractions remained unchanged and very low. There was a significant umbilical vein-artery difference for FFA at all sample times $(p<0.05)$. Maternal FFA concentrations rose after the Intralipid infusion (Friedman's two-way analysis of variance, $p$ $=0.0007)$. This was mirrored by a corresponding rise in perfusate vein-artery difference as can be seen in Figure 1, although not statistically significant $(p>0.05)$.

Plasma lipid profiles. Figure 2 shows the individual fatty acid concentrations associated with FFA, triacylglycerol, and

Table 1. Physiologic status of the experimental animals $(n=10)$

\begin{tabular}{lccc}
\hline & & & $\begin{array}{c}\text { Wilcoxon's signed } \\
\text { rank }\end{array}$ \\
\hline Maternal pH & $7.38 \pm 0.02$ & $7.33 \pm 0.03$ & $p=0.05$ \\
Maternal PaO $_{2}(\mathrm{kPa})$ & $13.8 \pm 0.89$ & $13.5 \pm 1.19$ & $p=0.78$ \\
$\begin{array}{c}\text { Maternal arterial } \\
\text { blood pressure } \\
\quad(\mathrm{mm} \mathrm{Hg})\end{array}$ & $65 \pm 7$ & $61 \pm 6$ & $p=0.03$ \\
$\begin{array}{c}\text { Placental perfusion } \\
\text { pressure (mm Hg) }\end{array}$ & $10 \pm 2$ & $10 \pm 2$ & $p=0.89$ \\
$\begin{array}{c}\text { Perfusate/maternal } \\
\text { antipyrine ratio }\end{array}$ & $0.6 \pm 0.1$ & $0.6 \pm 0.1$ & $p=0.52$ \\
\hline
\end{tabular}

Results are means \pm SEM.
Free fatty acid

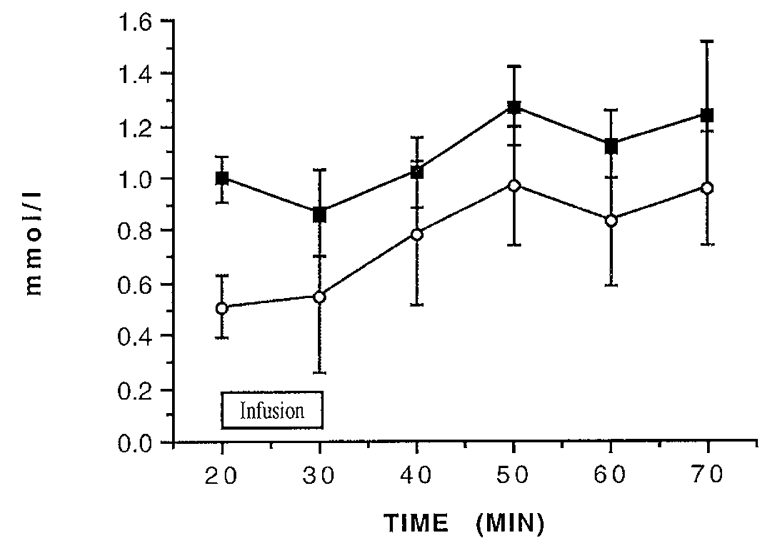

Triacylglycerol

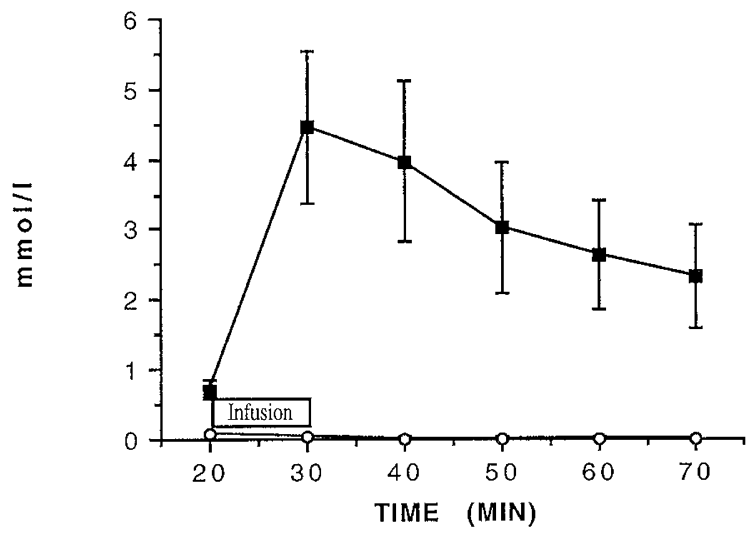

Phospholipid

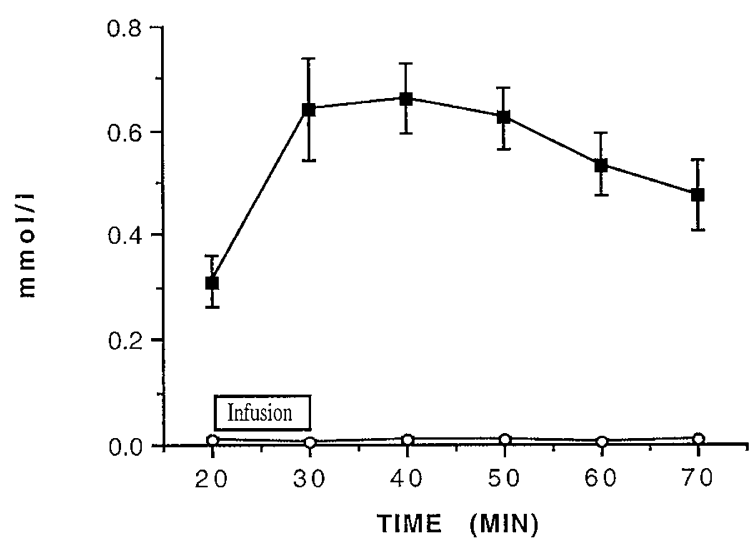

Figure 1. Fatty acid concentrations in maternal plasma (四) and perfusate vein-artery difference $(O)$ for the FFA, triacylglycerol, and phospholipid fractions during and after the period of the infusion of Intralipid into the maternal circulation. Results are means with the SEM shown as vertical bars.

phospholipid in the maternal circulation before and after the Intralipid infusion. At the end of the infusion period, the compositions of the maternal plasma triacylglycerol showed increases in $\mathrm{C} 16: 0(p<0.05), \mathrm{C} 18: 0(p<0.01), \mathrm{C} 18: \ln 9(p$ $<0.01), \mathrm{C} 18: 2 \mathrm{n} 6(p=0.01)$, and C18:3n3 $(p=0.01)$ acids. Increases in the maternal plasma phospholipid fraction were seen in C16:0 $(p=0.01), \mathrm{C} 16: 1 \mathrm{n} 7(p<0.01), \mathrm{C} 18: 0(p<$ $0.05), \mathrm{C} 18: 1 \mathrm{n} 9(p<0.01), \mathrm{C} 18: 2 \mathrm{n} 6(p<0.05)$, and C22:6n3 

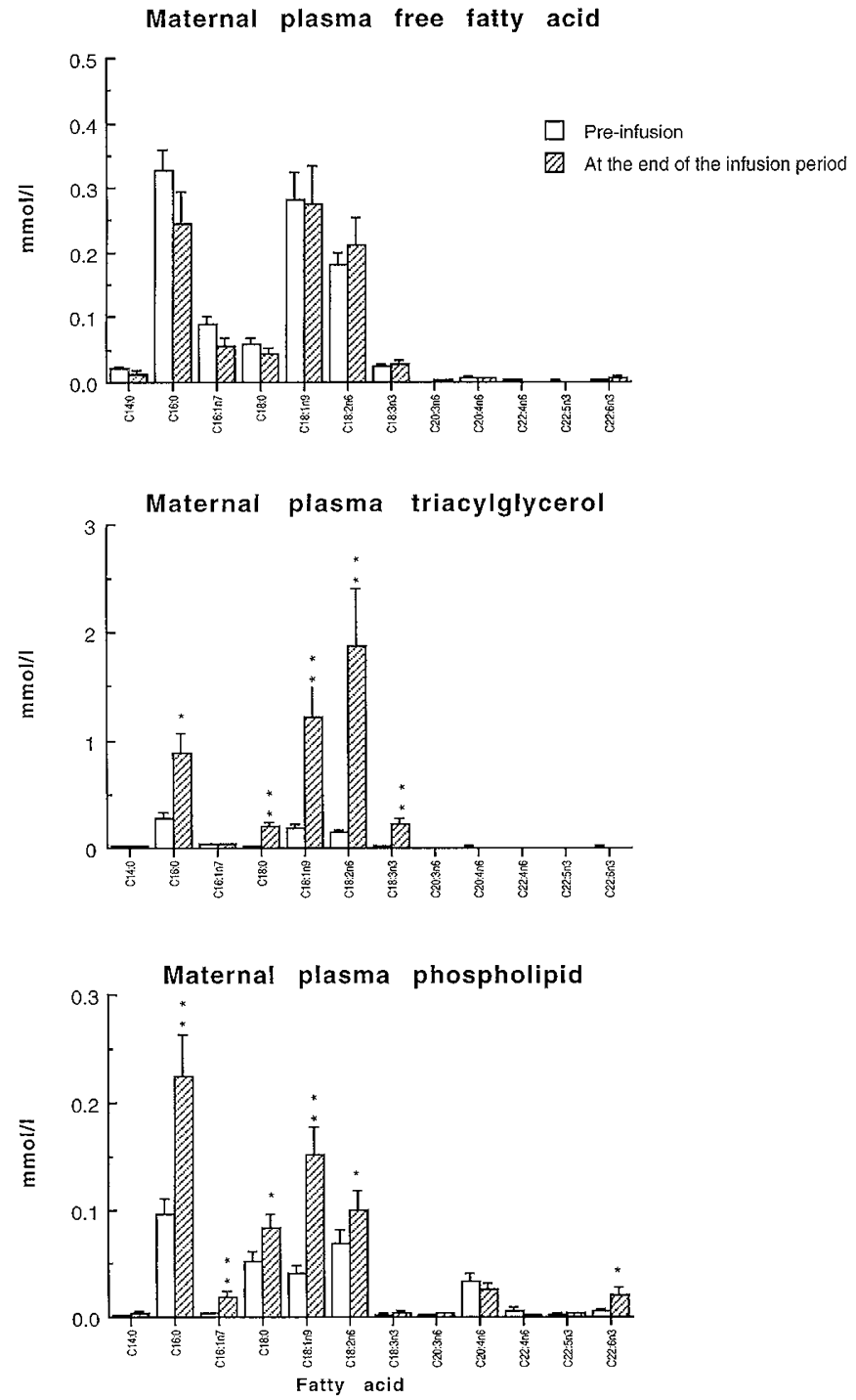

Figure 2. The concentrations of individual fatty acids in maternal plasma FFA, triacylglycerol, and phospholipid fractions before and at the end of the period of infusion of Intralipid. On this and subsequent graphs the mean is represented by the height of the columns and the SEM by the vertical bars; the differences between pre- and postinfusion concentrations are shown ${ }^{*} p<0.05$, $* * p \leq 0.01$ (Wilcoxon's signed rank test).

$(p<0.05)$ acids. These fatty acids represent the major fatty acids of the Intralipid emulsion in the triacylglycerol and phospholipid fractions, respectively (Fig. 3). The fatty acid composition of the maternal FFA fraction was not altered significantly at the end of the infusion or at any time thereafter up to the final sampling point of $40 \mathrm{~min}$ after the infusion.

By the end of the infusion period, the only significant changes in concentration in the perfusate vein-artery difference were for $\mathrm{C} 18: 2 \mathrm{n} 6$ and $\mathrm{C} 18: \ln 9(p<0.05)$. These are the main fatty acid components of Intralipid. By 20 min after the end of the infusion, the maximum increase in the vein-artery difference for FFA occurs when compared with the preinfusion vein-artery difference. By this time there were increases in $\mathrm{C} 16: 0(p<0.05), \mathrm{C} 18: 0(p<0.01), \mathrm{C} 18: 3 \mathrm{n} 3(p<0.01)$, and C20:3n6 $(p<0.05)$ as well as C18:1n9 $(p=0.01)$ and C18:2n6 $(p<0.01)$. Because over $90 \%$ of the lipid in Intralipid is triacylglycerol, five of these six fatty acids represent

\section{Intralipid Triacylglycerol}

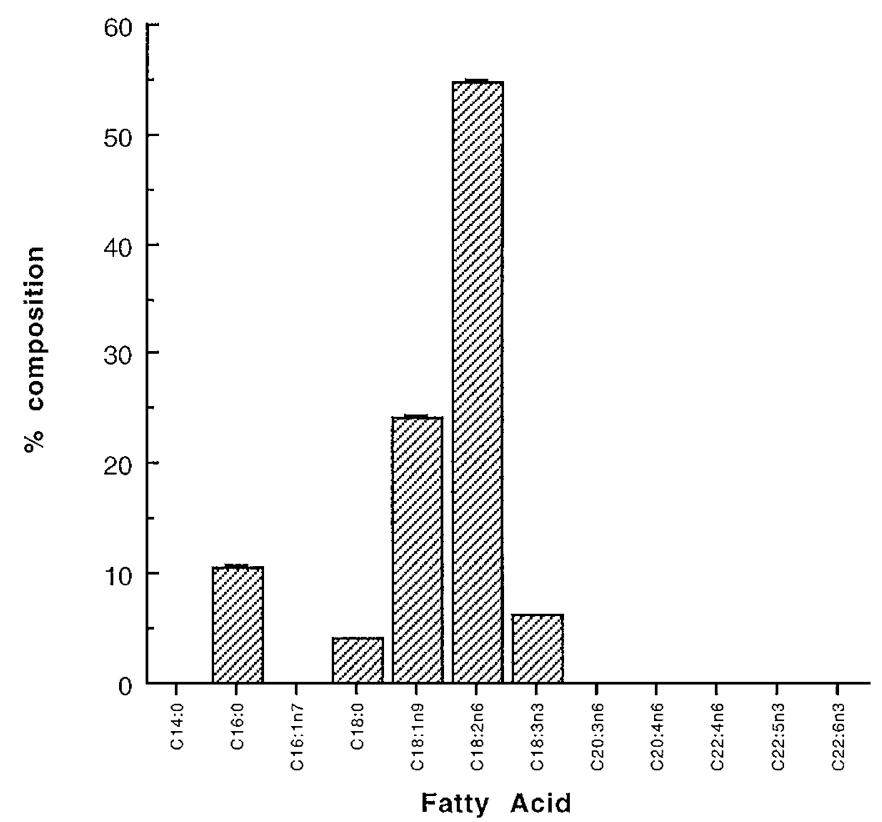

Intralipid Phospholipid

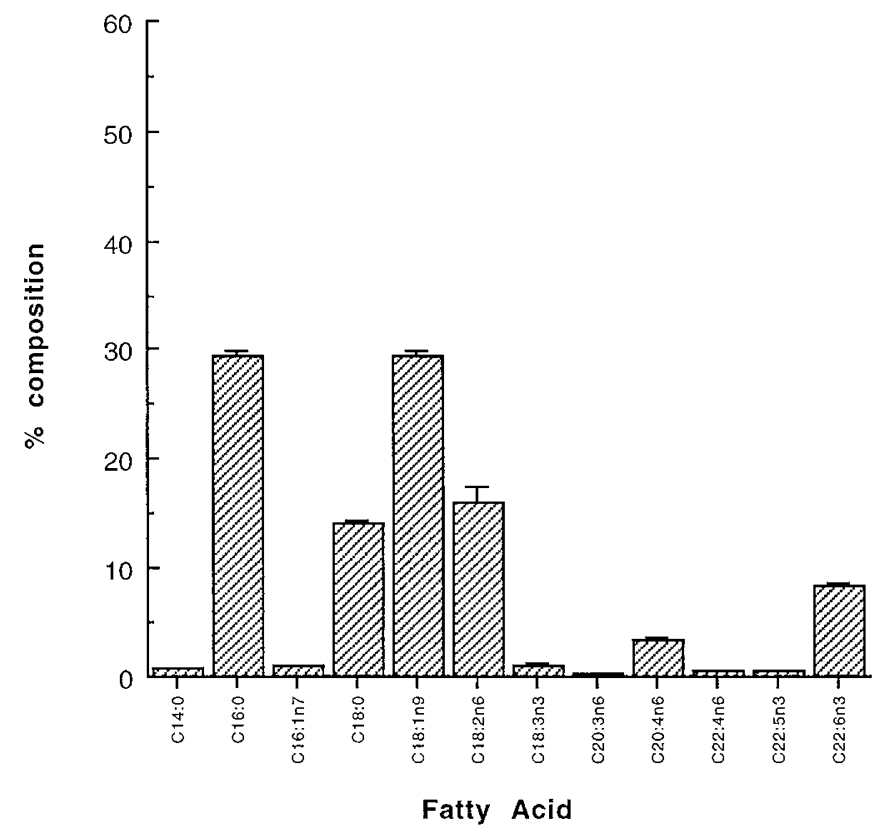

Figure 3. The individual fatty acid composition of the triacylglycerol and phospholipid fractions of Intralipid.

the dominant esterified fatty acids within Intralipid (see Fig. 3). Figure 4 shows these data for individual FFA concentrations in the umbilical vein-artery difference fraction before and $20 \mathrm{~min}$ after the end of the Intralipid infusion. The data for the vein-artery difference declined after this time, although at 30 and $40 \mathrm{~min}$ after the end of the Intralipid infusion, the veinartery difference for $\mathrm{C} 18: 0(p<0.01), \mathrm{C} 18: \ln 9(p<0.05)$, $\mathrm{C} 18: 2 \mathrm{n} 6(p<0.05)$, and $\mathrm{C} 18: 3 \mathrm{n} 3(p<0.01)$ remained 

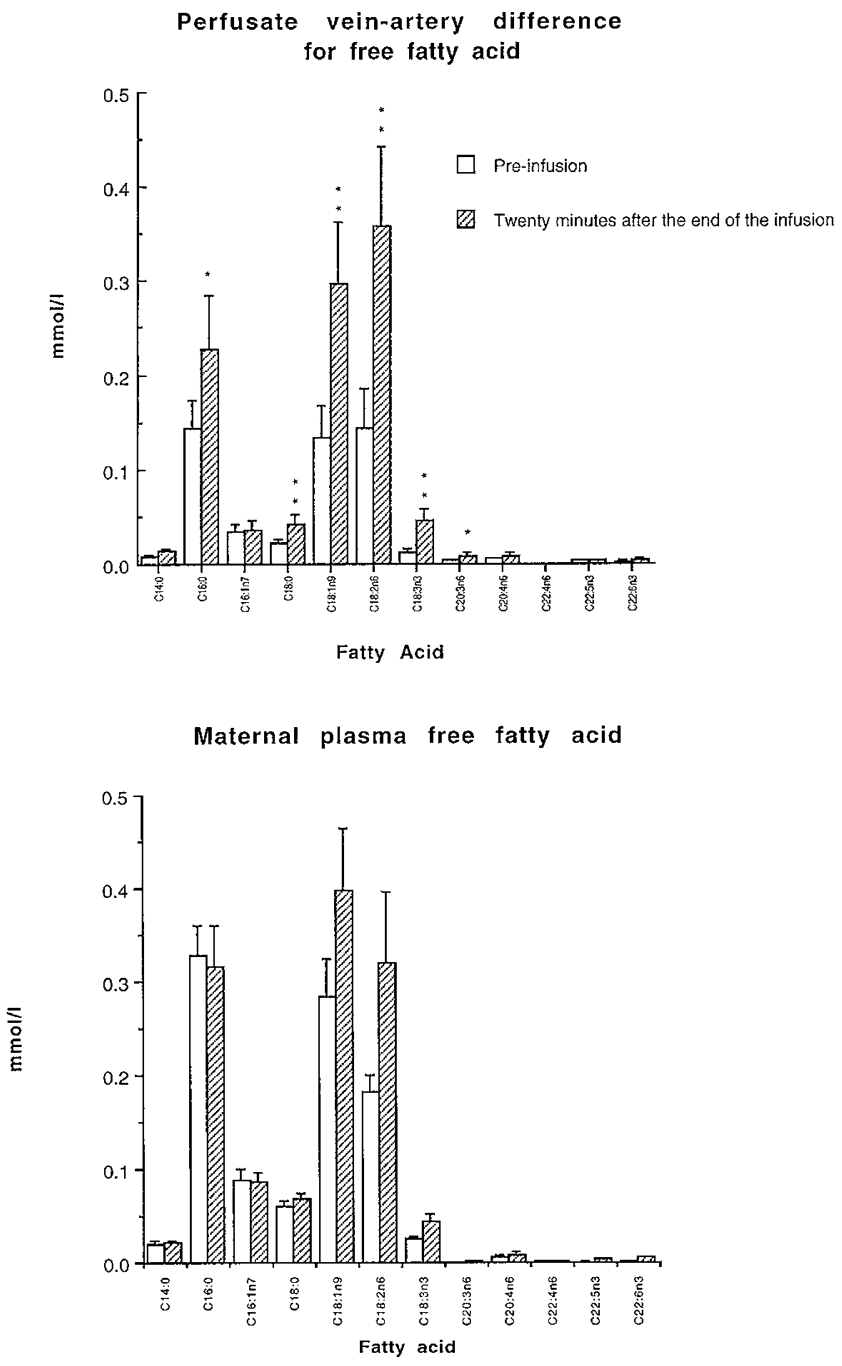

Figure 4. The maternal plasma and perfusate vein-artery difference individual FFA before the infusion of Intralipid and $20 \mathrm{~min}$ after the end of the period of infusion. The mean is represented by the height of the columns and the SEM by the vertical bars; the differences between pre- and postinfusion concentrations are shown $* p<0.05, * * p \leq 0.01$ (Wilcoxon's signed rank test).

significantly elevated above pre-Intralipid infusion levels. This time was our last sampling point.

\section{DISCUSSION}

There have been previous experiments in animals manipulating maternal diet and examining the effect on fetal lipids $(18-20)$. Feeding pregnant rats (21) or rabbits (19) a diet with added corn oil (rich in C18:2n6) led to an increase in the amount of $\mathrm{C} 18: 2 \mathrm{n} 6$ in fetal tissues. In the guinea pig, supplementing the diet of dams with maize oil or beef tallow (18) altered the composition of fetal fats in that they came to resemble more closely the profile of the maternal diet. Other studies in which the essential fatty acid composition of the maternal diet was altered in rats showed that this resulted in altered fetal brain growth (22) and impaired learning behavior in the offspring (23). Given that C18:2n6 and other essential fatty acids are major components of structural lipids in the CNS, this sequence of events is consistent with the fact that the mammalian fetus cannot synthesize polyenoic derivatives de novo and is dependent on transplacental flux of essential fatty acids.

Manipulation of the maternal diet has consequences for the development of the lung as well as the brain; altering the relative proportions of saturated and unsaturated fats in the diet of pregnant rats resulted in significant changes in the type of phospholipids present in fetal lung (24). Phospholipids represent about $70 \%$ of surfactant by weight (25), and changes in composition may alter the protection conferred against the neonatal respiratory distress syndrome.

In the human, there have been fewer studies, presumably because of ethical and cultural restraints, but at least one intervention study has demonstrated that alteration of the fatty acid composition of maternal diet in early gestation altered the fatty acid composition of fetal tissue (26). There is also some data from mothers given cod liver oil or sesame oil before surgical abortion which suggested that the fatty acids derived from these triacylglycerols may cross the placenta (27). An observational study has shown higher levels of C20:4 in the cord blood of infants of mothers taking vegetarian diets (20).

There have been other reports examining the effect of altering lipids in the maternal circulation by infusing a fat emulsion i.v. $(28,29)$. An infusion of triacylglycerol emulsion (Intralipid, an emulsion of soya bean oil rich in C18:2 and C18:1) given i.v. to the pregnant rabbit appeared to be hydrolyzed by the placenta, allowing increased amounts of FFA to cross the placenta (28). Circulating triacylglycerols are bound to very low density lipoproteins and these authors also demonstrated within rabbit placenta the presence of lipoprotein lipase, an enzyme essential for the hydrolysis of circulating triacylglycerols. An infusion of Intralipid into pregnant women resulted in a large umbilical vein-artery difference for FFA and for triacylglycerols at delivery and the profile of cord blood FFA was altered toward that of the i.v. emulsion (29).

Our experiments differ in that the methodology reported here allowed us to examine changes in transfer across the placenta serially with time after the Intralipid infusion whereas the previous experiments have investigated the effects on fetal body composition or single fetal blood samples.

In this series of experiments a short infusion of an exogenous fat emulsion resulted in a significant alteration in maternal circulating lipids. The fatty acid composition of the triacylglycerol and phospholipid fractions of Intralipid is shown in Figure 3. The concentration of triacylglycerol in maternal plasma increased significantly as did the phospholipid concentration and the composition of these fractions in maternal plasma reflected more closely that of the infused Intralipid. After termination of the infusion triacylglycerol concentrations in the maternal circulation returned to baseline values more rapidly than did the concentrations of phospholipid. This is in keeping with the shorter half-life of triacylglycerol in the circulation (30).

The FFA profile of the outflowing perfusate changed in composition to reflect that of the Intralipid emulsion with the appearance of greater concentrations of C18:2n6 and C18:1n9. This change in perfusate fatty acid profile was sustained throughout the remainder of the experiment. This would sug- 
gest that the composition of fatty acid released by the placenta into the umbilical circulation was influenced by a placental pool of fatty acid. This implies that the placenta has the ability to take up fatty acids hydrolyzed from triacylglycerol and phospholipid in the maternal circulation and release these fatty acids into the fetal circulation. The infusion of Intralipid into the mother is likely to influence the composition of the placental pool of fatty acid derived from these maternal fractions and result in a different mix of fatty acid reaching the fetus. Although the infused triacylglycerol was cleared from the maternal circulation in these experiments relatively quickly, taking less than $10 \mathrm{~min}$ in all, the effects of the infusion on placental transfer of fatty acid was more sustained.

In a series of 33 pregnant women undergoing elective cesarean section, the mean maternal plasma FFA concentration was $1.0 \mathrm{mmol} / \mathrm{L}$ and the umbilical vein-artery difference for FFA was $0.036 \mathrm{mmol} / \mathrm{L}$ (31). The umbilical venous-arterial differences in FFA concentrations were much smaller than those observed in the in situ rabbit perfusions reported here despite roughly similar maternal concentrations. Although the absolute amounts may be small relative to the rabbit, these may be physiologically significant because of the longer gestation and slower growth rate.

Because decreased transfer of nutrients into the fetus has been documented in many forms of intrauterine growth retardation, there have been attempts to evaluate whether increasing fetal nutrient availability prevents experimental growth retardation in animal models $(32,33)$. In the report by De Prins et al. (33) the improved survival rate in the offspring of supplemented rats was not mediated through differences in placental weight, fetal weight, or fetal liver weight, i.e. maternal hyperalimentation did influence fetal outcome but not by simply stimulating gross placental or fetal growth. Extrapolation of these results to other species would be inappropriate except to say that fetal outcome and/or growth can be markedly affected by the plane of maternal nutrition in late gestation, at least after simple experimental ischemic placental failure. There is epidemiologic evidence that some adult diseases may be linked to adverse environmental influences during fetal life (34). Interventions which modulate the passage of nutrients from mother to fetus may have a role in preventing mortality and morbidity in both the short- and long-term, although this remains controversial (35).

\section{REFERENCES}

1. European Atherosclerosis Society Study Group 1987 Strategies for the prevention of coronary heart disease: a policy statement of the European Atherosclerosis Society. Eur Heart J 8:77- 88

2. Barker DJP, Winter PD, Osmond C, Margetts B, Simmonds SJ 1989 Weight in infancy and death from ischaemic heart disease. Lancet 2:577-580
3. Barker DJP, Bull AR, Osmond C, Simmonds SJ 1990 Fetal and placental size and risk of hypertension in adult life. BMJ 301:259-262

4. Hahn P, Koldovsky O 1976 Late effect of premature weaning on blood cholesterol levels in adult rats. Nutr Rep Int 13:87-91

5. Subbiah MTR, Yunker RL, Menkays A, Poe B 1985 Premature weaning-induced changes of cholesterol metabolism in guinea pigs. Am J Physiol 249:E251-E256

6. Mott GE, Jackson EN, McMahan CA, McGill HC 1990 Cholesterol metabolism in adult baboons is influenced by infant diet. J Nutr 120:243-251

7. James D 1990 Diagnosis and management of fetal growth retardation. Arch Dis Child 65:390-394

8. Chang A, Abell D, Beischer N, Wood C 1977 Trial of intravenous therapy in women with low urinary estriol excretion. Am J Obstet Gynecol 127:793-797

9. Stephenson TJ, Stammers JP, Hull D 1990 Maternal to fetal transfer of free fatty acids in the in situ perfused rabbit placenta. J Dev Physiol 13:117-123

10. Stephenson TJ, Stammers JP, Hull D 1991 Effects of altering umbilical flow and umbilical free fatty acid concentration on transfer of free fatty acids across the rabbit placenta. J Dev Physiol 15:221-227

11. Elphick MC, Flecknell P, Hull D, McFadyen IR 1980 Plasma free fatty acid umbilical venous-arterial concentration differences and placental transfer of ${ }^{14} \mathrm{C}$ palmitic acid in pigs. J Dev Physiol 2:347-356

12. Dole V 1956 A relation between non-esterified fatty acids in plasma and the metabolism of glucose. J Clin Invest 35:150-154

13. Folch J, Lees M, Sloane-Stanley GH 1957 A simple method for the isolation and purification of total lipids from animal tissues. J Biol Chem 226:497-509

14. Glass RL 1971 Alcoholysis, saponification and preparation of fatty acid methyl esters. Lipids 6:919-925

15. Brodie BB, Axelrod J, Soberman R, Levy BB 1949 The estimation of antipyrine in biological materials. J Biol Chem 179:25-29

16. Stephenson TJ, Stammers JP, Hull D 1993 Placental transfer of free fatty acids: Importance of fetal albumin concentration and acid-base status. Biol Neonate 63:273280

17. Stammers JP, Stephenson TJ, Colley JA, Hull D 1995 Fetal lipoproteins and placental release of esterified lipids. Reprod Fertil Dev (in press)

18. Pavey DE, Widdowson EM 1975 Influence of dietary fat intake of the mother on composition of body fat of new born guinea pigs. Proc Nutr Soc 34:107A-108A

19. Stammers JP, Elphick MC, Hull D 1983 Effect of maternal diet during late pregnancy on fetal lipid stores in rabbits. J Dev Physiol 5:395-404

20. Stammers JP, Hull D, Abraham R and McFadyen IR 1989 High C20:4 levels in the cord blood of infants of mothers on vegetarian diets. Br J Nutr 61:89-97

21. Miguel SG, Abraham S 1976 Effect of maternal diet on fetal hepatic lipogenesis. Biochim Biophys Acta 424:213-234

22. McKenna MC, Campagnoni AT 1979 Effects of pre- and postnatal essential fatty acid deficient diet on brain development and myelination. J Nutr 109:1195-1204

23. Lamptey MS, Walker BL 1976 A possible essential role for dietary linolenic acid in the development of the young rat. J Nutr 106:86-93

24. Nelson GH, McPherson J, Perling L, Ciechan R 1980 The effect of maternal dietary fat on fetal pulmonary maturation in rats. Am J Obstet Gynecol 138:466-467

25. Jobe A 1984 Fetal lung maturation and the respiratory distress syndrome. In: Beard RW, Nathanielsz PW (eds) Fetal Physiology and Medicine, 2nd Ed. Marcel Dekker, New York, pp 317-351

26. Watanabe Y 1967 Study on fetal lipid metabolism. J Jpn Obstet Gynaecol Soc 19:1187-1196

27. Robertson AF, Sprecher H 1968 A review of human placental lipid metabolism and transport. Acta Paediatr Scand 183(suppl):3-17

28. Elphick MC, Hull D 1977 Rabbit placental clearing-factor lipase and transfer to the foetus of fatty acids derived from triglycerides injected into the mother. J Physiol 273:474-487

29. Elphick MC, Filshie GM, Hull D 1978 The passage of fat emulsion across the human placenta. Br J Obstet Gynaecol 85:610-618

30. Margolis S, Capuzzi D 1972 Serum lipoproteins synthesis and metabolism. In: Nelson GJ (ed) Blood Lipids and Lipoproteins. Quantitation, Composition and Metabolism. Wiley Interscience, New York, pp 825

31. Hendrickse W, Stammers JP, Hull D 1985 The transfer of free fatty acids across the human placenta. Br J Obstet Gynaecol 92:945-952

32. Charlton V, Johengen M 1987 Fetal intravenous nutritional supplementation ameliorates the development of embolization induced growth retardation in sheep. Pediatr Res 22:55-61

33. De Prins F, Hill DJ, Milner RDG, Van Assche A 1988 Effect of maternal hyperalimentation on intrauterine growth retardation. Arch Dis Child 63:733-736

34. Barker DJP, Martyn CN 1992 The maternal and fetal origins of cardiovascular disease. J Epidemiol Community Health 46:8-11

35. Elford J, Shaper AG, Whincup P 1992 Early life experience and cardiovascular disease-ecological studies. J Epidemiol Community Health 46:1-8 